\title{
Spontaneous community-acquired PVL- producing Staphylococcus aureus mediastinitis in an immunocompetent adult - a case report
}

\author{
Josselin Brisset ${ }^{1,2}$, Thomas Daix ${ }^{1,3^{*}}$ (D) Jérémy Tricard ${ }^{4}$, Bruno Evrard ${ }^{1}$, Philippe Vignon ${ }^{1,3}$, Olivier Barraud $d^{3,5}$
} and Bruno François ${ }^{1,3}$

\begin{abstract}
Background: Mediastinitis caused by hematogenous spread of an infection is rare. We report the first known case of community-acquired mediastinitis from hematogenous origin in an immunocompetent adult. This rare invasive infection was due to Panton-Valentine Leucocidin-producing (PVL+) methicillin-susceptible Staphylococcus aureus (MSSA).

Case presentation: A 22-year-old obese man without other medical history was hospitalized for febrile precordial chest pain. He reported a cutaneous back abscess 3 weeks before. CT-scan was consistent with mediastinitis and blood cultures grew for a PVL+ MSSA. Intravenous clindamycin (600 mg ti.d) and cloxacillin (2 g q.i.d.), secondary changed for fosfomycin ( $4 \mathrm{~g}$ q.i.d.) because of a related toxidermia, was administered. Surgical drainage was performed and confirmed the presence of a mediastinal abscess associated with a fistula between the mediastinum and right pleural space. All local bacteriological samples also grew for PVL+ MSSA. In addition to clindamycin, intravenous fosfomycin was switched to trimethoprim-sulfamethoxazole after 4 weeks for a total of 10 weeks of antibiotics.

Conclusions: We present the first community-acquired mediastinitis of hematogenous origin with PVL+ MSSA. Clinical evolution was favorable after surgical drainage and 10 weeks of antibiotics. The specific virulence of MSSA PVL+ strains played presumably a key role in this rare invasive clinical presentation.
\end{abstract}

Keywords: Community-acquired mediastinitis, MSSA, Panton-valentine Leucocidin

\section{Background}

Mediastinitis is mainly due to deep sternal wound infection, esophageal perforation, or descending necrotizing mediastinitis originating from ear-nose-throat (ENT) infections and exceptionally to hematogenous spread [1]. In case of hematogenous spread, mediastinitis is usually healthcare-acquired $[2,3]$.

\footnotetext{
* Correspondence: thomas.daix@chu-limoges.fr

${ }^{1}$ Réanimation polyvalente, CHU Dupuytren, 2 avenue Martin Luther King, F-87000 Limoges, France

${ }^{3}$ Inserm CIC 1435 \& UMR 1092, CHU Dupuytren, F-87000 Limoges, France

Full list of author information is available at the end of the article
}

Panton Valentin Leucocidin-producing (PVL+) methicillin-susceptible Staphylococcus aureus (MSSA) was mostly described in community-acquired necrotizing pneumonia, bone and joint infections and skin and soft tissue infections such as furunculosis [4]. As far as we know, we present the first case of a community-acquired mediastinitis caused by MSSA. The strain was PVL+ and seemed to belong to USA300 strains [5] which are increasingly associated with invasive infections.

C C The Author(s). 2020 Open Access This article is licensed under a Creative Commons Attribution 4.0 International License, which permits use, sharing, adaptation, distribution and reproduction in any medium or format, as long as you give appropriate credit to the original author(s) and the source, provide a link to the Creative Commons licence, and indicate if changes were made. The images or other third party material in this article are included in the article's Creative Commons licence, unless indicated otherwise in a credit line to the material. If material is not included in the article's Creative Commons licence and your intended use is not permitted by statutory regulation or exceeds the permitted use, you will need to obtain permission directly from the copyright holder. To view a copy of this licence, visit http://creativecommons.org/licenses/by/4.0/ The Creative Commons Public Domain Dedication waiver (http://creativecommons.org/publicdomain/zero/1.0/) applies to the data made available in this article, unless otherwise stated in a credit line to the data. 


\section{Case presentation}

A 22-year-old obese $\left(\mathrm{BMI}=38 \mathrm{~kg} / \mathrm{m}^{2}\right)$ man without other medical history was admitted to the emergency department (ED) for precordial chest pain worsening for 5 days and radiating to the back and shoulders. The patient had low dysphagia, progressive-onset dyspnea and unproductive cough for 2 days but without fever or shiver. This patient, usually living in Illinois, had worked as a teacher in France for the last 8 months and did not travel outside Western Europe and the USA.

On admission, the patient presented with fever $\left(38.5^{\circ} \mathrm{C}\right)$, tachypnea (RR: $\left.30 / \mathrm{min}\right)$ and required $31 / \mathrm{min}$ of oxygen $\left(\mathrm{SpO}_{2}: 97 \%\right)$ but had no signs of respiratory distress. Lung auscultation revealed decreased breath sounds in the right lower lobe. Blood pressure and heart rate were normal. There was no evidence for a dental, oro-pharyngeal infection, or cervical cellulitis. Second questioning of the patient highlighted a skin lesion described as an abscess in the back 3 weeks before admission which was successfully treated by Povidone-Iodine alcohol but it was absent on the current clinical examination. None of his relatives or colleagues described any signs of skin infection.

Blood tests were consistent with a marked inflammatory syndrome with a high leucocytes level $\left(41,000 / \mathrm{mm}^{3} ; 82 \%\right.$ of neutrophils) and a CRP of $450 \mathrm{mg} / \mathrm{l}$. Procalcitonin was $3.3 \mathrm{ng} / \mathrm{ml}$ and lactate was $1.31 \mathrm{mmol} / \mathrm{l}$. Neck and chest CT-scan revealed an enlargement of the mediastinum due to a diffuse mediastinal infiltration with a moderate bilateral pleural effusion (Fig. 1), without lung parenchymal, pharyngeal and neck abnormalities or jugular venous thrombosis. Esophageal perforation was ruled out by a Barium swallow test and esophagogastroduodenoscopy. Community-acquired mediastinitis being suspected,

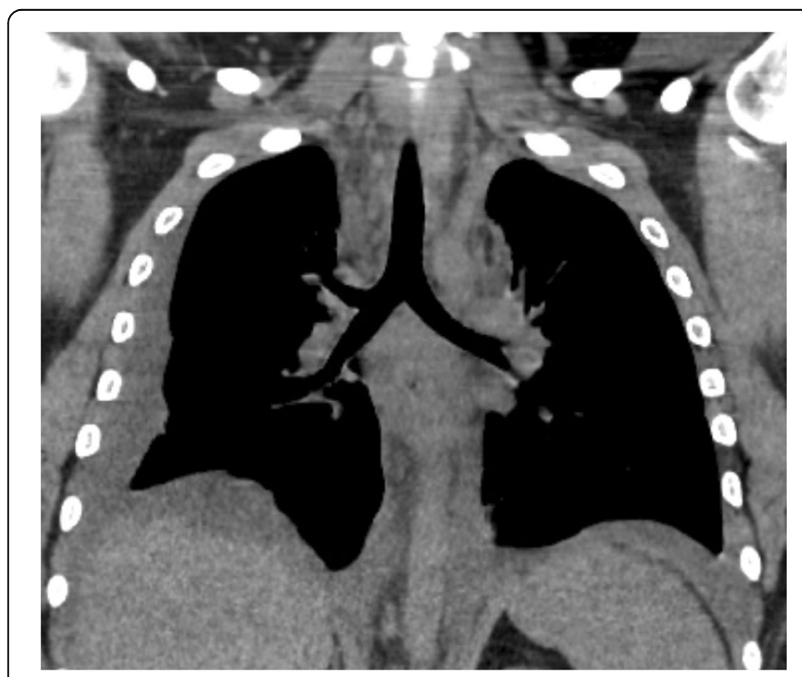

Fig. 1 Chest $C T$ scan of the initial presentation of the mediastinitis, with diffuse mediastinal infiltration empirical antibiotic treatment with intravenous amoxicillin/clavulanic acid 1 g q.i.d. was started in the ED and the patient was transferred in the intensive care unit (ICU).

On ICU admission, right pleural tap evidenced purulent fluid with Gram positive cocci. Cultures grew for a PVL+ MSSA. The genomic analysis revealed that the Staphylococcus aureus strain belonged to a CC8 clonal complex. In addition to PVL, the strain exhibited enterotoxins $\mathrm{K}, \mathrm{Q}$, and an agr1 allele (Identibac S. aureus Genotyping DNA microarray, Alere Technologies, Jena, Germany). Blood cultures sampled at ICU admission were also positive for the same PVL+ MSSA.

Transthoracic and transesophageal echocardiography ruled out infective endocarditis. On day 2 , the antibiotic regimen was switched to intravenous cloxacillin $(2 \mathrm{~g}$ q.i.d.) and clindamycin (600 mg t.i.d.) as an anti-toxinic PVL adjunctive treatment. On day 5, a diffuse skin rash consistent with a toxidermia appeared and lead to the replacement of cloxacillin with fosfomycin $(4 \mathrm{~g}$ q.i.d.) with no skin rash recurrence.

On day 4, cervicotomy and right thoracotomy allowed the evacuation of a right pleural empyema and mediastinal abscesses, and evidenced the presence of a fistula between the mediastinum and right pleural space (Fig. 2). All surgical samples from the mediastinum and the right pleura grew for the same MSSA strain.

Blood cultures obtained systematically on days 8,15 and 22 were negative. Subsequent echocardiography and chest CT-scan depicted the regression of both the mediastinal infiltration and residual abscesses (Fig. 3a and b). The patient was discharged from ICU on day 36 and from hospital on day 42 without any complication. Chest CT-scan performed two months later confirmed the complete disappearance of mediastinal abscesses (Fig. 3c).

On top of clindamycin, intravenous fosfomycin was carried on for 4 weeks, then switched to trimethoprimsulfamethoxazole until hospital discharge (day 42). Clindamycin and trimethoprim-sulfamethoxazole were

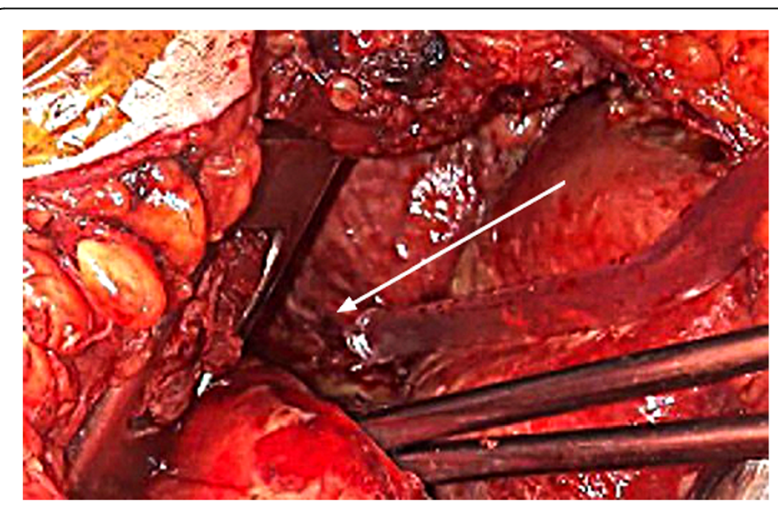

Fig. 2 This picture taken during surgery, evidenced the fistula (white arrow) from the mediastinum to the right pleura 


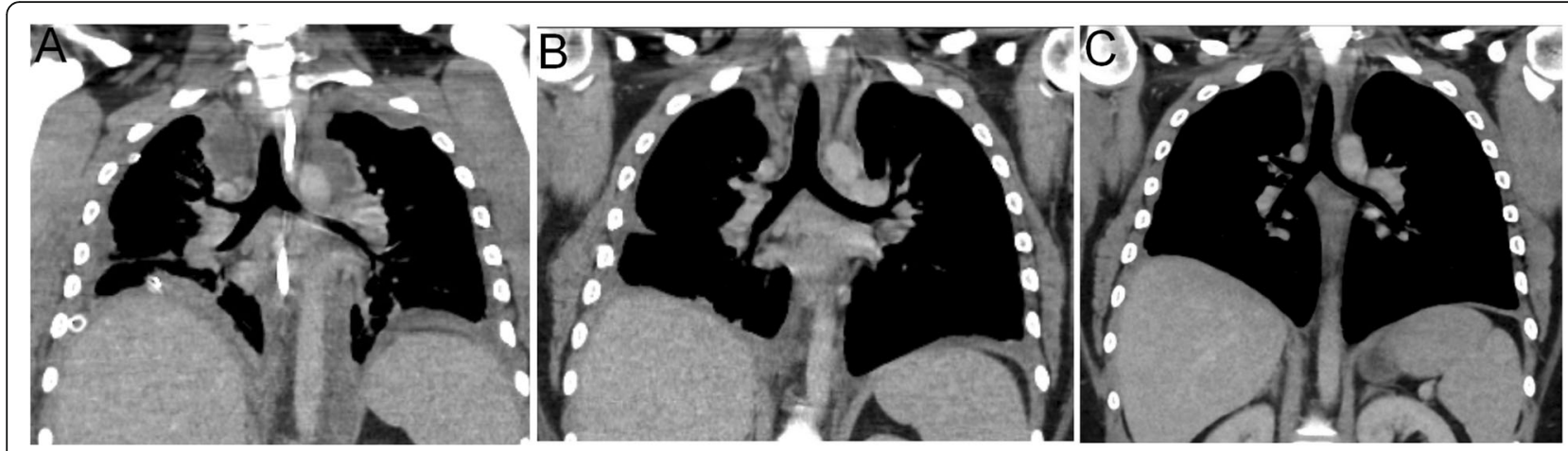

Fig. 3 (a) Day 7 CT scan- acme of the mediastinal infiltration, with abscesses formation (3 days after surgery); (b) CT scan at M1 after intensive care unit admission; (c) CT scan at M2 after intensive care unit admission

continued for 6 more weeks for a total of 10 weeks of treatment.

No immunodepression was evidenced with normal immunoglobulin levels, no complement pathway defect, negative HIV testing and antibody titers of previously administered vaccines (diphtheria, tetanus, HBV) without any abnormal response.

Long-term antibiotics and early surgery benefited our patient which is now doing well and was able to go back to the United States of America (USA) on June 6th, 2019.

\section{Discussion and conclusions}

The MSSA strain was PVL+ and a member of CC8 clonal complex. Regarding the genetic marker interference methodology, this strain belongs to USA300 strains [5]. The prevalence of this strain seems to increase and to be associated with invasive infection [6].

Undoubtedly, the PVL toxin may have significantly contributed to the severity of the disease. PVL is expressed by major methicillin-resistant Staphylococcus aureus (MRSA) clones, which have now spread throughout the world [7] even if PVL+ SA remains especially present in the USA, with $48.1 \%$ of MRSA strains and $11.5 \%$ of MSSA strains being identified in this region (8.2\% in northeast, region of origin of our patient) [8]. In contrast in France, the majority of strains expressing PVL are MSSA strains. As in our patient, PVL+ SA strains affect mainly young adults without underlying disorder [9] and are more often found in communityacquired infections than in hospital-acquired infections [10]. In community-acquired infections, PVL is an independent marker of severity regardless the resistance of the Staphylococcus aureus strain to methicillin [11]. PVL is known to lyse neutrophils and boost the inflammatory cascade which can explain the progressive tissue necrosis in case of invasive infection associated with necrotic skin and soft tissue infection such as furuncles [12] and community-acquired pneumonia [13]. In our patient, these properties presumably contributed to the development of a fistula from which facilitated the spread of the local infection from the mediastinum to the right pleural space. PVL+ SA toxins have been most frequently associated with skin and soft tissue infections (folliculitis and cutaneous abscesses), and with necrotizing pneumonia [4]. Since the medical history, clinical examination and CT-scan did not show any signs of dental, pharyngeal or cervical infections, we can assume that the skin abscess which developed 3 weeks before the severe infection could be the source of the initial bacteremia and secondary location in the chest.

Three main etiologies of acute infective mediatinitis are traditionally distinguished: deep sternal wound infection following cardiovascular and thoracic surgery, esophageal perforation and descending necrotizing mediastinitis originating from dental, pharyngeal or cervical infections [14]. Overall mortality of acute mediastinitis ranges between 20\% (esophageal perforation) to 30\% (descending necrotizing mediastinitis) [1]. Exceptionally, primary mediastinitis may result from a bacteremia. To our knowledge, only two cases have been reported so far. Both of them were healthcare-associated mediastinitis, one in a dialysis patient with an arteriovenous shunt due to MRSA which was not identified as PVL+ [2] and one associated with a central venous catheter and due to Candida species [3].

Treatment of community-acquired acute mediastinitis is based on antimicrobial therapy and control of the source of infection using surgical debridement. With the exception of mediastinitis developing in the postoperative setting which requires rapid surgical debridement within $24 \mathrm{~h}$ [15], there are currently no guidelines for the timing of the surgery. Multiple surgical management is required in approximatively $30 \%$ of patients [16]. There are currently no guidelines for empirical antibiotic therapy which should be adapted on the expected origin of mediastinitis. With the exception of deep sternal wound infections which are commonly related to SA, 
polymicrobial infection with flora from the oral cavity and/or the upper respiratory tract is common in other causes of mediastinitis [1]. In our patient, the empirical therapy with amoxicillin-clavulanic acid targeted aerobic and anaerobic oral and upper gastro-intestinal bacteria. Antibiotic regimen was adapted secondary to MSSA identification using high-dose of cloxacillin since betalactam antibiotics can increase PVL secretion in case of insufficient concentration in vitro [17]. In addition, clindamycin was associated since it strongly inhibits PVL secretion in vitro, as linezolid [17].

PVL-producing MSSA can result in communityacquired infective mediastinitis secondary to bacteremia after a cutaneous abscess in young immunocompetent adult.

\section{Abbreviations}

BMI: Body mass index; CRP: C-reactive protein; ED: Emergency department; HBV: Hepatitis B virus; HIV: Human immunodeficiency virus; ICU: Intensive care unit; MRSA: Methicillin-resistant Staphylococcus aureus; MSSA: Methicillinsusceptible Staphylococcus aureus; PCT: Procalcitonin; PVL: Panton-Valentine Leucocidin; RR: Respiratory rate; TTE: Transthoracic echocardiography; USA: United States of America; WBC: White blood cells

\section{Acknowledgements}

NA

\section{Authors' contributions}

$J B, T D, B E, J T, P V$, and BF took care of the patient. OB analyzed the samples. $J B$ and TD gathered the data and drafted the manuscript. PV, BE, OB and BF critically reviewed the manuscript. All authors approved the final version.

\section{Funding}

None.

\section{Availability of data and materials}

Data sharing is not applicable to this article as no datasets were generated or analyzed during the current case.

\section{Ethics approval and consent to participate}

NA

\section{Consent for publication}

Written informed consent was obtained from the patient for publication of this case report and any accompanying images. A copy of the written consent is available for review by the Editor-in-Chief of this journal.

\section{Competing interests}

The authors declare that they have no competing interests.

\section{Author details}

'Réanimation polyvalente, CHU Dupuytren, 2 avenue Martin Luther King, F-87000 Limoges, France. ${ }^{2}$ Maladies infectieuses, CHU Dupuytren, F-87000 Limoges, France. ${ }^{3}$ Inserm CIC 1435 \& UMR 1092, CHU Dupuytren, F-87000 Limoges, France. ${ }^{4}$ Chirurgie cardiaque, CHU Dupuytren, F-87000 Limoges, France. ${ }^{5}$ Laboratoire de Bactériologie - Virologie - Hygiène, CHU Dupuytren, F-87000 Limoges, France.

Received: 2 April 2020 Accepted: 7 May 2020

Published online: 19 May 2020

\section{References}

1. Pastene B, Cassir N, Tankel J, Einav S, Fournier PE, Thomas P, Leone M. Mediastinitis in the intensive care unit patient: a narrative review. Clin Microbiol Infect. 2020;26(1):26-34
2. Chang $\mathrm{CH}$, Huang JY, Lai PC, Yang CW. Posterior mediastinal abscess in a hemodialysis patient - a rare but life-threatening complication of Staphylococcus bacteremia. Clin Nephrol. 2009;71:92-5.

3. Er F, Nia AM, Caglayan E, Gassanov N. Mediastinitis as a complication of central venous catheterization. Infection. 2010;38:509.

4. Lina G, Piémont Y, Godail-Gamot F, Bes M, Peter MO, Gauduchon V, Vandenesch F, Etienne J. Involvement of Panton-valentine leukocidinproducing Staphylococcus aureus in primary skin infections and pneumonia. Clin Infect Dis. 1999;29:1128-32.

5. Bowers JR, Driebe EM, Albrecht V, McDougal LK, Granade M, Roe CC, Lemmer D, Rasheed JK, Engelthaler DM, Keim P, Limbago BM. Improved Subtyping of Staphylococcus aureus Clonal Complex 8 Strains Based on Whole-Genome Phylogenetic Analysis. mSphere. 2018;3(3):pii:e00464-17.

6. McCaskill ML, Mason EO Jr, Kaplan SL, Hammerman W, Lamberth LB, Hultén KG. Increase of the USA300 clone among community-acquired methicillinsusceptible Staphylococcus aureus causing invasive infections. Pediatr Infect Dis J. 2007;26(12):1122-7.

7. Tristan A, Bes M, Meugnier H, Lina G, Bozdogan B, Courvalin P, Reverdy ME, Enright MC, Vandenesch F, Etienne J. Global distribution of Panton-valentine Leukocidin-positive methicillin-resistant Staphylococcus aureus, 2006. Emerg Infect Dis. 2007;13:594-600.

8. Brown ML, O'Hara FP, Close NM, Mera RM, Miller LA, Suaya JA, AmrineMadsen $\mathrm{H}$. Prevalence and sequence variation of panton-valentine leukocidin in methicillin-resistant and methicillin-susceptible Staphylococcus aureus strains in the United States. J Clin Microbiol. 2012;50:86-90.

9. Gillet $Y$, Issartel B, Vanhems P, Fournet JC, Lina G, Bes M, Vandenesch F, Piémont Y, Brousse N, Floret D, Etienne J. Association between Staphylococcus aureus strains carrying gene for Panton-valentine leukocidin and highly lethal necrotising pneumonia in young immunocompetent patients. Lancet. 2002;359(9308):753-9.

10. Bádue Pereira MF, Bando SY, Sasagawa SM, da Silva CB, Mimica MJ, Berezin EN. Panton-valentine positive Staphylococcus aureus in communityacquired and hospital-acquired pediatric infections. Pediatr Infect Dis J. 2019;38(10):1068-70.

11. Gijón M, Bellusci M, Petraitiene B, Noguera-Julian A, Zilinskaite V, Sanchez Moreno P, Saavedra-Lozano J, Glikman D, Daskalaki M, Kaiser-Labusch P, Falup-Pecurariu O, Montagnani C, Prieto L, Gené A, Trumpulyte G, Kulecnikova I, Lepe JA, Cercenado E, Kudinsky R, Makri A, Huppertz HI, Bleotu L, Cocchi P, García-Hierro P, Vitkauskiene A, Fortuny C, Zukovskaja V, Neth O, Santos M, Rokney A, Petra M, Lixandru R, Galli L, Guillén S, Chaves F, Rojo Conejo P. Factors associated with severity in invasive communityacquired Staphylococcus aureus infections in children: a prospective European multicentre study. Clin Microbiol Infect. 2016;22(7):643.e1-6.

12. Lina G, Piémont Y, Godail-Gamot F, Bes M, Peter MO, Gauduchon V, Vandenesch F, Etienne J. Involvement of Panton-valentine leukocidinproducing Staphylococcus aureus in primary skin infections and pneumonia. Clin Infect Dis. 1999;29(5):1128-32.

13. Labandeira-Rey M, Couzon F, Boisset S, Brown EL, Bes M, Benito Y, Barbu EM, Vazquez V, Höök M, Etienne J, Vandenesch F, Bowden MG. Staphylococcus aureus Panton-Valentine leukocidin causes necrotizing pneumonia. Science. 2007;315(5815):1130-3.

14. Chen K-C, Chen J-S, Kuo S-W, Huang PM, Hsu HH, Lee JM, Lee YC. Descending necrotizing mediastinitis: a 10-year surgical experience in a single institution. J Thorac Cardiovasc Surg. 2008;136:191-8.

15. Abu-Omar Y, Kocher GJ, Bosco P, Barbero C, Waller D, Gudbjartsson T, Sousa-Uva M, Licht PB, Dunning J, Schmid RA, Cardillo G. European Association for Cardio-Thoracic Surgery expert consensus statement on the prevention and management of mediastinitis. Eur J Cardiothorac Surg. 2017; 51(1):10-29

16. Prado-Calleros HM, Jiménez-Fuentes E, Jiménez-Escobar I. Descending necrotizing mediastinitis: systematic review on its treatment in the last 6 years, 75 years after its description. Head Neck. 2016;38(Suppl 1):E2275-83.

17. Dumitrescu O, Boisset S, Badiou C, Bes M, Benito Y, Reverdy ME, Vandenesch F, Etienne J, Lina G. Effect of antibiotics on Staphylococcus aureus producing Panton-valentine leukocidin. Antimicrob Agents Chemother. 2007:51:1515-9.

\section{Publisher's Note}

Springer Nature remains neutral with regard to jurisdictional claims in published maps and institutional affiliations. 